\title{
Electrified powertrains for wheel-driven non-road mobile machinery
}

\author{
Josef Markus Ratzinger ${ }^{1} \cdot$ Simon Buchberger ${ }^{1} \cdot$ Helmut Eichlseder $^{1}$
}

Received: 17 July 2020 / Accepted: 8 October 2020 / Published online: 22 November 2020

(c) The Author(s) 2020

\begin{abstract}
Already enacted carbon-dioxide $\left(\mathrm{CO}_{2}\right)$ limiting legislations for passenger cars and heavy duty vehicles, drive motivations to consider electrification also in the sector of non-road mobile machinery. Up to now, only the emissions of the vehicles themselves have been restricted. However, to capture the overall situation, a more global assessment approach is necessary. The study described in this article applies a tank-to-wheel and an extended well-to-wheel approach based on simulations to compare three different powertrains: a battery electric drive, a parallel electric hybrid drive, and a series electric hybrid drive. The results show that electrification is not per se the better solution in terms of keeping $\mathrm{CO}_{2}$ emissions at a minimum, as battery electric powertrains are accountable for the lowest as well as the highest possible $\mathrm{CO}_{2}$ emissions of all powertrains compared. A battery electric machine is not economically competitive if its battery has to last a whole working day. Parallel hybrid systems do not achieve much of an advantage in terms of $\mathrm{CO}_{2}$ emissions. In this global assessment approach, the most promising propulsion system for wheel-driven-mobile-machinery appears to be the series hybrid system, which shows to offer up to $20 \%$ of $\mathrm{CO}_{2}$ saving potential compared to the current machine.
\end{abstract}

Keywords Non-road mobile machinery $\cdot \mathrm{NRMM} \cdot$ Mobile machinery $\cdot \mathrm{CO}_{2}$ emissions $\cdot$ Tank-to-wheel $\cdot$ Well-to-wheel $\cdot$ Battery electric $\cdot$ Parallel hybrid $\cdot$ Series hybrid

\begin{tabular}{ll}
\multicolumn{2}{l}{ Abbreviations } \\
AUX & Auxiliary \\
b & Burned \\
Batt & Battery \\
BSFC & Brake-specific fuel consumption \\
CD & Charge-depleting \\
CS & Charge-sustaining \\
DT & Drive train \\
eff & Effective \\
el & Electric \\
EM & Electric motor \\
HM & Hydraulic motor \\
HP & Hydraulic pump \\
Hyd & Hydraulic \\
i & Internal \\
ICE & Internal combustion engine \\
l & Loss \\
NRMM & Non-road mobile machinery
\end{tabular}

Josef Markus Ratzinger

ratzinger@ivt.tugraz.at

1 Institute of Internal Combustion Engines and Thermodynamics, Research Area "Propulsion Systems", Graz University of Technology, Graz, Austria

$\begin{array}{ll}\text { PE } & \text { Power electronics } \\ \text { pH } & \text { Parallel hybrid } \\ \text { Recup } & \text { Recuperation } \\ \text { sH } & \text { Series hybrid } \\ \text { TM } & \text { Traction motor } \\ \text { tot } & \text { Total } \\ \text { TtW } & \text { Tank-to-wheel } \\ \text { WH } & \text { Working hydraulic system } \\ \text { WM } & \text { Working motor } \\ \text { WtW } & \text { Well-to-wheel }\end{array}$

\section{Introduction}

For the vast majority of mobile machinery, the dominant power source is a diesel engine. The share of "non-road mobile machinery" (NRMM) in total European fuel consumption of passenger and goods transport was $11 \%$ in 2010 [1]. This corresponds to $2 \%$ of total European carbondioxide $\left(\mathrm{CO}_{2}\right)$ emissions in the same reference year. Current European legislation for NRMM covers a broad range of machinery typically used off the road. The legislation determines different performance classes for which emission limits are set respectively, ranging from machines like 
small handheld gardening equipment up to locomotives and stationary generators. The legislation in force is EU-stage $\mathrm{V}$ and is the first that limits the particulate number. It also provides a further reduction of particle mass and nitrogen oxide emissions.

It is most likely that ongoing discussions about air quality in European cities will lead to a further lowering of allowed emissions by law. Possible scenarios include emission-free protection zones in and around urban areas. These measures will eventually also affect the applicability of mobile machinery.

Another fact motivating the present study is the recent development towards an additional $\mathrm{CO}_{2}$-limiting legislation. Since 2019, the certification process of heavy duty vehicle includes the assessment of emission values according to EU VI as well as a vehicle-individual evaluation by a longitudinal vehicle dynamics simulation software (VECTO $=$ Vehicle Energy Consumption Calculation Tool) [2]. By 2025 , this should result in $\mathrm{CO}_{2}$ reductions of $15 \%$ compared to the reference year 2019 , and to minus $30 \%$ by 2030 . This in turn limits the energy consumption of heavy duty vehicles, because the fuel consumption directly correlates with $\mathrm{CO}_{2}$-emissions. Thus, technology that is accounted emission free is necessary to achieve a high number of $\mathrm{CO}_{2}$ reduction. Typically, the legislation for mobile machinery lags behind the emissions legislation of heavy duty vehicles. By not taking into account the energy carrier production, however, current legislation follows a simplified approach, called tankto-wheel, in the assessment of emissions. The consequence of this simplification is that electric- and hydrogen-powered drives account for zero emissions, even though they both in fact cause emissions during a complete life cycle. Depending on the production process of the energy carrier, the according emissions vary considerably. Therefore, this study argues for a consideration of the total emissions, which requires at least a well-to-wheel or better a cradle-to-grave analysis to reveal the powertrain with the lowest emissions.

First insights into fuel saving potential of electrified mobile machinery powertrains can be gained by looking at already published studies. According to current literature, fuel savings between 5 and $40 \%$ could be achieved, depending on the powertrain structure and the machine usage [3-6]. Independently of the powertrain structure, a more cyclic working process (frequent successive acceleration and braking or load lifting and lowering) of the machine leads to a higher energy recovery potential and, consequently, higher fuel saving potential. Of course, this potential still needs to be exploited by a well-adapted operating strategy and layout of the vehicle. A prerequisite for recuperation, however, is the use of a rechargeable energy storage system.

In the present study, focus is laid on battery electric and partially electrified powertrains for wheel-driven construction machinery, since the potential of recovering energy is considered particularly high with such machines. For example, potential energy can be recovered when lowering a load and kinetic energy during braking. In this way, the total energy demand can be reduced. The investigation focuses on machines with a dominate share of traction-drive use during operation including wheel loaders, industrial trucks, mobile excavators, dump trucks, telescopic handlers, and dumpers (Fig. 1).

The assessment of $\mathrm{CO}_{2}$ emissions follows a simulationbased approach to compare and evaluate three different electrified powertrain topologies: a battery electric drive, a parallel electric hybrid drive, and a series electric hybrid drive. The data for these simulations are taken from measurements of a real operational cycle. In addition to considering $\mathrm{CO}_{2}$ emissions, the simulations analyse the overall energy consumption. At the end of the article, a critical look is taken on the implications regarding the feasibility of implementing the three electrified powertrains analysed for actual use.

\section{Methods}

In the automotive context, a simulation of longitudinal vehicle dynamics is state-of-the-art for modelling and optimizing of propulsion systems [7]. Typically, a backward calculation is performed in which speed and altitude (or gradient) are specified over time used to calculate the necessary power at the wheel. Along the efficiency chain from the wheel to the engine, each energy converter is represented by a stationary efficiency map. The advantage of using stationary efficiency maps is the low numerical effort. Although neglecting dynamic phenomena can lead to large deviations in
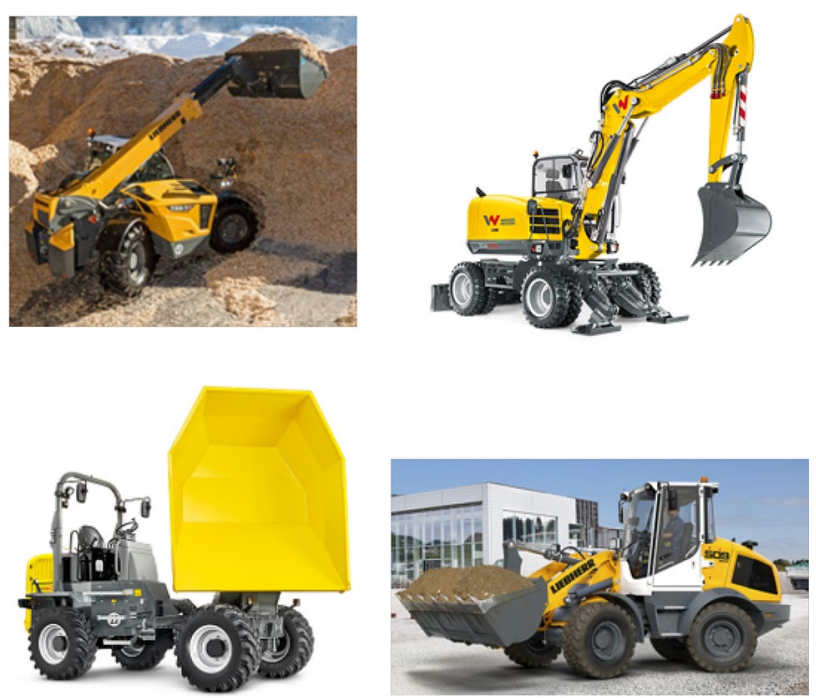

Fig. 1 Mobile machinery with a high share of traction-drive use. (source: Liebherr, Wacker Neuson) 
short time intervals, an accurate prediction of the total fuel consumption is possible [7]. Test cycles like New European Driving Cycle (NEDC) or Worldwide harmonized Light vehicles Test Cycle (WLTC) are commonly used. With Real-Driving-Emissions (RDE) legislation in force, manufacturers use different self-defined cycles to involve various relevant driving situations for the vehicle's main usage.

The method applied in this study is based on the idea of a backward calculation using stationary efficiency maps of each energy converter to gain the overall energy consumption, but was further developed to suit the study of mobile machinery. The most important difference to be considered compared to other vehicles like cars is that beyond wheel propulsion, the propulsion of the work hydraulic system also needs to be considered. For mobile machinery, an analysis of the drive train itself through a typical simulation of longitudinal vehicle dynamics based on velocity and gradient over time would only account for isolated driving operations. Mobile machinery, however, often uses the work hydraulic system and the drive train at the same time; as an example, one can think of the filling of the bucket of a wheel loader. At the moment the bucket touches the ground and enters the pile of bulk material, there is additional friction between the bucket and the ground, which is not covered by a simulation of longitudinal vehicle dynamics. The present study covers phenomena like this by carrying out simulations based on measurements gained from a real machine operating in different typical transient working situations.

The study is conducted in two main steps: first, the energy consumption of three different propulsion systems is calculated. Second, based on step one, the $\mathrm{CO}_{2}$ emissions of all drive trains are calculated to be able to compare electric and hybrid powertrains.

\subsection{The machine studied}

This study focuses on the powertrain of a 9-ton material handling machine with a payload of 4.5 tons. The power source for the current machine is a EU-stage-V diesel engine with $100 \mathrm{~kW}$ power. The effective power of the internal combustion engine is used to propel three main consumer groups.

The first consumer group is the drive train. Representative for the state-of-the-art with wheel-driven machinery, the machine has a hydrostatic pump-motor system (Fig. 2), which has the major advantages of having a high power density, a variable transmission ratio, as well as simple reversing by swivelling of the pump. A disadvantage of this system is the reduced efficiency at high transport speeds when the hydraulic motor is at a small swivelling angle [8]. The middle power chain in Fig. 2 illustrates the working hydraulic consumer group. It comprises the entire hydraulic system required to perform working tasks, for example, lifting a load. The third group of consumers, called AUX, combines all auxiliary

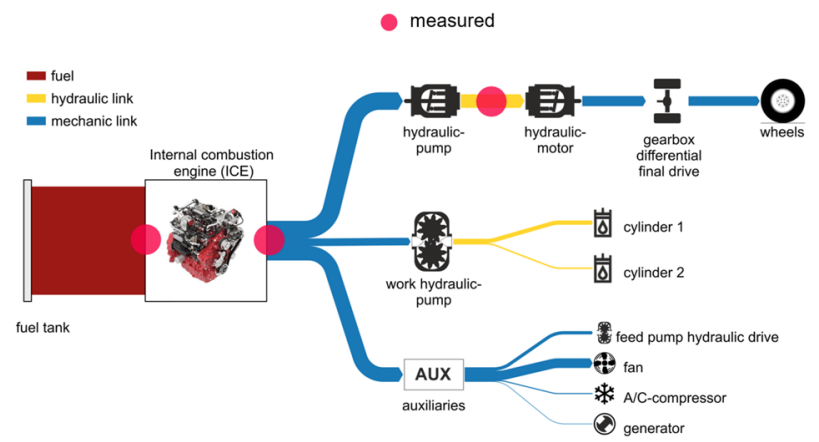

Fig. 2 Power measured in the studied power train

components that are additionally required for operating the machine. These include the feed pump, which is necessary for exchanging the heated hydraulic fluid between the hydraulic pump and hydraulic motor, the radiator fan, the air conditioning system, and the generator.

The material handling machine studied has a broad field of application. The most representative working task, a Y-cycle, was chosen for the comparison of the different electrified powertrains, because it requires wheel propulsion and additionally addresses the usage of the work hydraulic system. It is called Y-cycle, because when loading material from a pile into a transport vehicle by a material handling machine, normally, a Y-shaped track is driven. In a Y-cycle, dynamic measurements were performed by Liebherr Werk Telfs GmbH. In this study, the data gained are used to simulate electrified drive train topologies and to compute the power at the red points in Fig. 2. This set of measured/computed power is the basis for the MATLAB-based simulations carried out in this study.

The current hydrostatic powertrain propels the wheels with a series arrangement of a hydraulic variable axial piston pump and a variable axial piston motor (Fig. 2). The hydraulic power $P_{\text {Hyd }}$ between these two energy converters is calculated based on volume flow $\dot{V}$ and pressure difference $\Delta p$ for each time step:

$P_{\mathrm{Hyd}}=\dot{V} \cdot \Delta p$.

In a first step, the effective power at the cardan shaft $P_{\mathrm{HM}, \text { eff }}$ is computed incorporating efficiency maps of the hydraulic motor (arrow nr. 1 in Fig. 3). The effective power at the cardan shaft $P_{\mathrm{HM} \text {,eff }}$ represents the reference power for all considered electrified powertrains and is therefore of special interest for the following investigations. All powertrains considered must produce the same effective power at the cardan shaft. The wheels and axles are assumed to remain unchanged. The calculation is done based on an efficiency map and is performed for every measured data point by interpolating the value of the efficiency $\eta_{\mathrm{HM}}$ depending on the pressure difference $\Delta p$, the swivelling angle, and the 


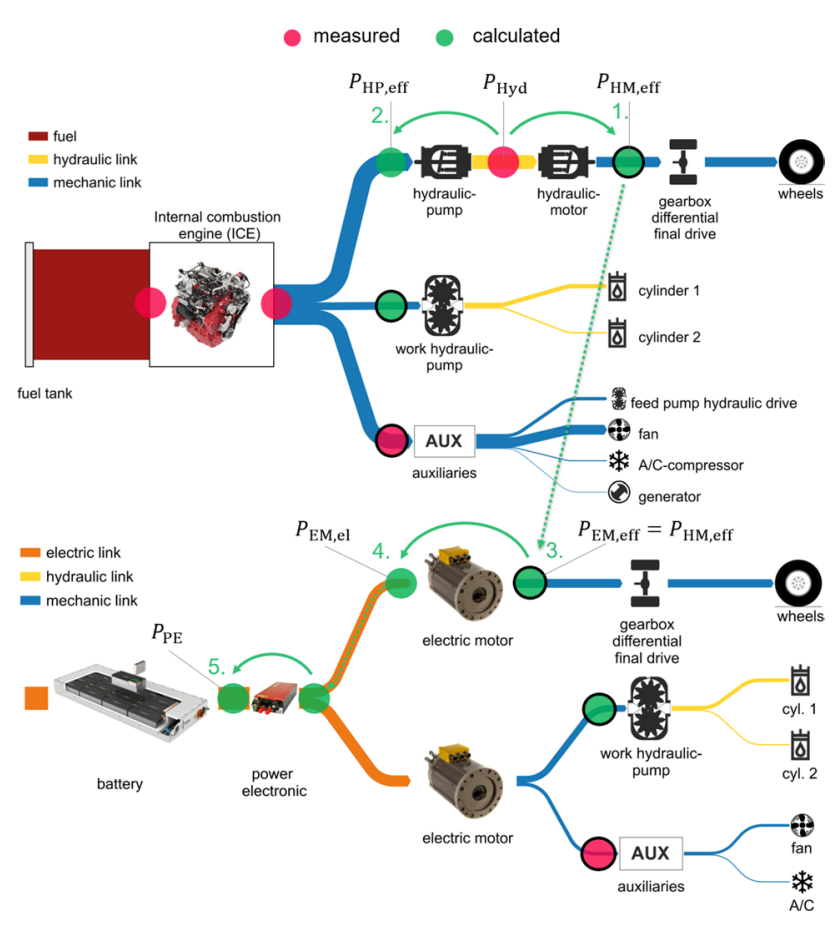

Fig. 3 Calculation method in a battery electric powertrain

rotational speed of hydraulic motor. It has to be noted that the following equations only represent the propulsion case:

$P_{\mathrm{HM}, \mathrm{eff}}=P_{\mathrm{Hyd}} \cdot \eta_{\mathrm{HM}}$.

The calculation of the effective power of the hydraulic pump $P_{\mathrm{HP}, \text { eff }}$ is based again on an efficiency map. The pump is driven by the internal combustion engine (ICE). The swivelling angle of the pump is measured and the pressure difference is the same as for the hydraulic motor. The effective power $P_{\mathrm{HP}, \text { eff }}$ at the crankshaft is the hydraulic power $P_{\mathrm{Hyd}}$ divided by the efficiency of the pump $\eta_{\mathrm{HP}}$ (arrow nr. 2 in Fig. 3):

$P_{\mathrm{HP}, \mathrm{eff}}=\frac{P_{\mathrm{Hyd}}}{\eta_{\mathrm{HP}}}$.

The effective power of the ICE $P_{\text {ICE }}$ is a calculated value based on engine control unit (ECU) parameters. Subtracting the effective power consumed by the hydraulic pump $P_{\mathrm{HP} \text {,eff }}$ from the total ICE power $P_{\mathrm{ICE}}$ gives the sum of the work hydraulic system and auxiliary power $P_{\mathrm{WH}, \mathrm{AUX}}$ :

$P_{\mathrm{WH}, \mathrm{AUX}}=P_{\mathrm{ICE}}-P_{\mathrm{HP}, \mathrm{eff}}$.

$P_{\mathrm{HM}, \mathrm{eff}}$ and $P_{\mathrm{WH}, \mathrm{AUX}}$ form the basis for the analysis of the three electrified powertrain topologies.

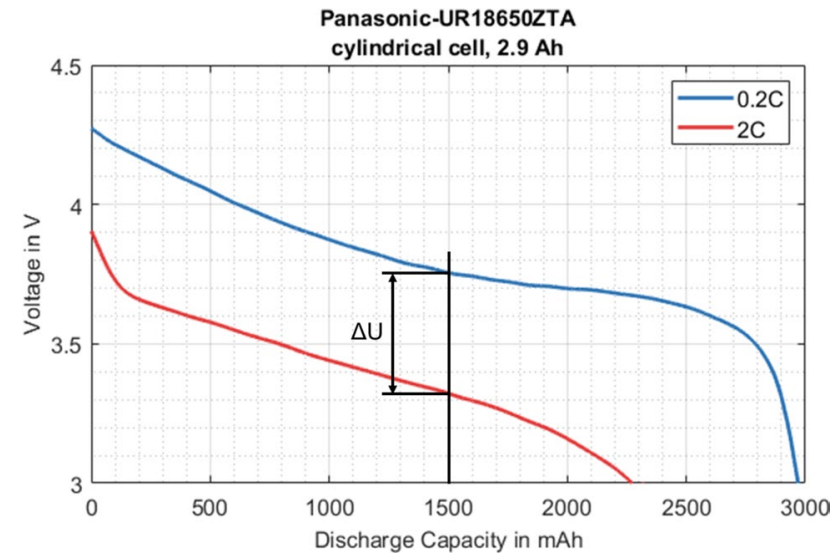

Fig. 4 Panasonic cylindrical cell UR18650ZTA: voltage over the discharge capacity at different $\mathrm{C}$ rates [12]

\subsection{Battery electric drive}

The battery electric drive consists of two electric motors independent from each other. The first motor is the drive train and the second motor propels the work hydraulic system as well as all auxiliaries. Starting with the power at the cardan shaft $P_{\mathrm{HM}, \text { eff }}$ (arrow nr. 3 in Fig. 3), a backward directed calculation is performed where an efficiency map of the electric motor $\eta_{\mathrm{EM}}$ is used (arrow nr. 4 in Fig. 3) [9]:

$P_{\mathrm{EM}, \mathrm{el}}=\frac{P_{\mathrm{HM}, \mathrm{eff}}}{\eta_{\mathrm{EM}}}$.

The efficiency of the power electronics $\eta_{\mathrm{PE}}$ depends on the input power and is over $95 \%$ in a wide operational range [10]. The effective power of the battery $P_{\mathrm{PE}}$ is the power consumed by the electric motor $P_{\mathrm{EM}, \mathrm{el}}$ divided by the efficiency of the power electronics $\eta_{\mathrm{PE}}$ (arrow nr. 5 in Fig. 3):

$P_{\mathrm{PE}}=\frac{P_{\mathrm{EM}, \mathrm{el}}}{\eta_{\mathrm{PE}}}$.

The battery is modelled as a non-ideal energy storage with losses. Since the majority of battery losses are due to conduction losses [11], a simplified model was used in which all losses are combined in the internal resistance of the battery. The internal resistance of a $320 \mathrm{kWh}$ battery system consisting of several 18650-type cells is calculated based on the manufacturer's data sheet [12]. The number of battery cells to be serially arranged is determined by the voltage level of a single cell and the assumption of a nominal system voltage level of $U=400 \mathrm{Vdc}$. The required total capacity is achieved by connecting several serially arranged strings in parallel. The internal resistance of a cell is calculated from the discharge characteristic (Fig. 4). 
At $1500 \mathrm{mAh}$ discharged capacity, the voltage is read at minimum and maximum discharge current ( $\Delta U$ in Fig. 4). It is calculated from the $\mathrm{C}$ rate which is a measure for the load of the battery:

$\mathrm{C}=\frac{I_{\text {const }}}{C_{\text {nominal }}}$.

$C_{\text {nominal }}$ is the nominal capacity of the battery. For the cylindrical cell considered, it is $2.9 \mathrm{Ah}$. The internal resistance $R_{\mathrm{i}}$ can be calculated based on Ohm's law:

$R_{\mathrm{i}}=\frac{\Delta U}{\Delta I}$.

$R_{\mathrm{i}}$ is $82 \mathrm{~m} \Omega$ for the considered cell. The whole battery pack has an internal resistance of $34 \mathrm{~m} \Omega$ in the considered 108 serial, 276 parallel configuration (108s276p). It has to be noted that neglecting the resistance of the cell connectors, contactors, fusing, and wiring of the battery system leads to an undefined underestimation of the losses. Based on the internal resistance, the power loss $P_{1}$ in the battery is calculated:

$P_{1}=R_{\mathrm{i}} \cdot I_{\text {Batt }}^{2}$.

The battery current $I_{\text {Batt }}$ is calculated based on the required power in the power electronics $P_{\mathrm{PE}}$ :

$I_{\mathrm{Batt}}=\frac{P_{\mathrm{PE}}}{U}$.

The power $P_{\text {Batt }}$ computes from the sum of the power supplied to the power electronics $P_{\mathrm{PE}}$ and the calculated losses within the battery $P_{1}$ :

$P_{\mathrm{Batt}}=P_{\mathrm{PE}}+P_{1}$.

Integrating the battery power results in the electrical energy demand:

$E_{\text {Batt }}=\int P_{\text {Batt }} \mathrm{d} t$.

The same method is used to calculate the power consumed by the second electric motor to drive the work hydraulic system and auxiliaries.

\subsection{Parallel hybrid}

The second electrified powertrain studied is the parallel hybrid. Compared to the current machine, almost the whole structure of the powertrain remains the same in the parallel hybrid. The only thing changing is that the effective power is generated by the ICE and a parallel arranged electric motor with battery and power electronics (Fig. 5). Recuperation is possible because of the battery.

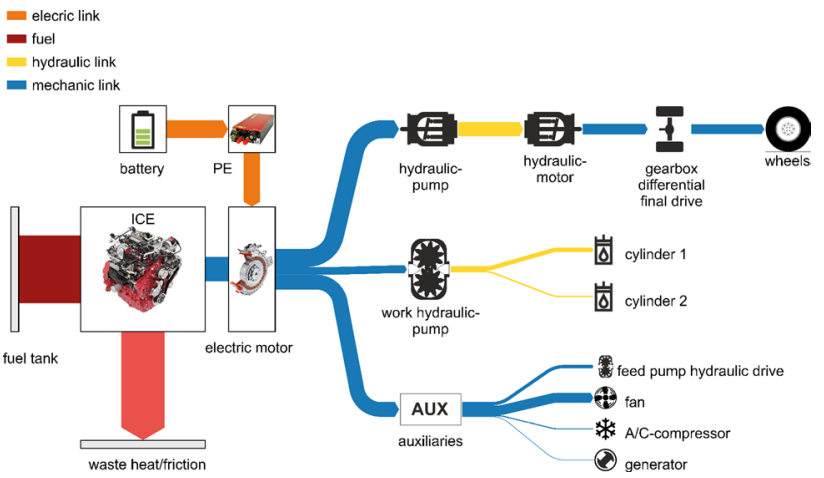

Fig. 5 Powertrain structure of a parallel hybrid

Both run at the same rotational speed, but the torque can be split up as wanted. Within the simulation, the engine and electric motor unit have to produce exactly the same effective power as the current machine at the crankshaft during the Y-cycle. The advantage of the parallel hybrid configuration is that energy can be recuperated while braking. The effective power produced by the hybrid-ICE and the electric motor at the common shaft $P_{\mathrm{Hyb}, \mathrm{eff}}$ is therefore the ICE power of the current machine $P_{\mathrm{ICE}}$ subtracted by the possible recuperation power $P_{\text {Recup }}$. This means that $P_{\text {Hyb,eff }}$ represents the mechanical energy effectively delivered by the combination of hybridICE and electric motor:

$P_{\mathrm{Hyb}, \mathrm{eff}}=P_{\mathrm{ICE}}-\left|P_{\text {Recup }}\right|$.

$P_{\text {Recup }}$ is obtained based on the measured hydraulic power $P_{\mathrm{Hyd}}$. In the phases where $P_{\mathrm{Hyd}}$ is negative, recuperation is possible. It is assumed that the parallel hybrid is equipped with an automatic clutch system to decouple the hybrid-ICE in recuperation phases. Otherwise, the ICE friction would consume a high share of the recuperable energy. However, $P_{\mathrm{Hyd}}$ is not the whole possible recuperation power in case of the parallel hybrid. Two things have to be considered, as well. First, the maximum power of the electric machine $P_{\mathrm{EM}, \max }=50 \mathrm{~kW}$, and second, the mean efficiency of the hydraulic pump $\bar{\eta}_{\text {HP,mean }}$ which is assumed to be $78 \%$. The efficiency considered for the hydraulic pump $\bar{\eta}_{\text {HP,mean }}$ is the mean efficiency of previous simulated cycle and takes into account that the effective power for recuperation is lowered by the efficiency of the pump. The electric motor is scaled to produce permanently $25 \mathrm{~kW}$ at maximum, but it is possible to overload the electric machine based on the temperature of the winding isolation [13]. It is assumed that recuperation phases are short in time and an overload factor of two is possible. The result is the available recuperation power $P_{\text {Recup }}$ at the common shaft of hybrid-ICE and electric motor:

$P_{\text {Recup }}=\max \left(\left(P_{\mathrm{Hyd}}<0\right) \cdot \bar{\eta}_{\mathrm{HP}, \text { mean }}, P_{\mathrm{EM}, \text { max }}\right)$. 
It is possible to downsize the hybrid-ICE, because additional power can be added by the electric motor arranged in parallel. For the comparative calculation performed, a $25 \%$ reduction in maximum power of the combustion engine is assumed. Above the full-load curve of the hybrid-ICE $P_{\text {Hyb-ICE,max }}$, power is added by the electric motor $P_{\text {EM-pH }}$ at the common rotational speed. This means that all demanded power $P_{\mathrm{Hyb}, \text { eff }}$ above the full-load curve of the hybrid-ICE $P_{\text {Hyb-ICE,max }}$ (Fig. 6) has to be added by the electric motor $P_{\mathrm{EM}-\mathrm{pH}}$ and is supplied by the battery. A negative sign indicates that energy is being taken from the battery. In recuperation phases, the sign is positive and means that energy is supplied to the battery:

$P_{\mathrm{EM}-\mathrm{pH}}=P_{\mathrm{Hyb}-\mathrm{ICE}, \max }\left(f\left(n_{\mathrm{ICE}}\right)\right)-P_{\mathrm{Hyb}, \mathrm{eff}}$.

To take into account all the losses along the efficiency chain from electric motor to battery, the supplied battery power is divided by the overall efficiency $\eta_{\mathrm{EM}-\mathrm{pH}, \mathrm{PE}, \mathrm{Batt}}$ :

$P_{\text {Batt-pH }}=\frac{P_{\text {EM-pH }}}{\eta_{\text {EM-pH,PE,Batt }}}$.

Integrating the effective battery power gives the total energy amount at the end of the simulation:
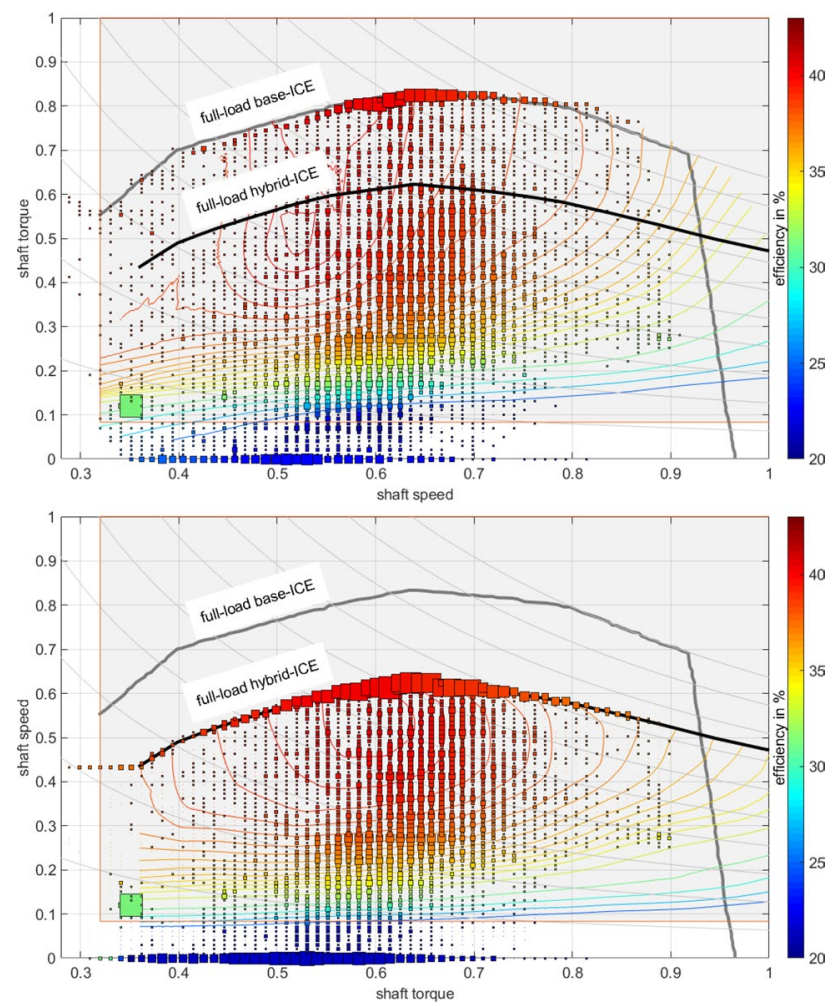

Fig. 6 Efficiency map of the current $100 \mathrm{~kW}$ ICE (top) and hybridICE (bottom) including full-load curves
$E_{\text {Batt-pH }}=\int P_{\text {Batt-pH }} \mathrm{d} t$.

The fuel consumed by the downsized hybrid-ICE is calculated on the basis of a stationary measured brake-specific fuel consumption (BSFC) map of a diesel engine with 75 $\mathrm{kW}$. Every load point (a rotational speed and torque pair) correlates with a BSFC point in the map. BSFC values are in gram diesel fuel per kWh effective energy at the crankshaft. For the simulation, it is assumed that the hybrid-ICE runs at the same rotational speed as the existing machine $n_{\text {ICE }}$. This assumption is made, because the work hydraulic system remains the same and its volume flow is based on the rotational speed of the engine:

$\mathrm{BSFC}=f\left(n_{\mathrm{ICE}}, M_{\mathrm{ICE}-\mathrm{pH}}\right)$.

Multiplying the BSFC value with the effective power of the hybrid-ICE $P_{\text {ICE-pH }}$ gives the fuel consumption $\dot{m}_{\mathrm{b}}$ in gram per hour:

$\dot{m}_{\mathrm{b}}=\mathrm{BSFC} \cdot P_{\mathrm{ICE}-\mathrm{pH}} \cdot$

Dividing the mass flow fuel burned $\dot{m}_{\mathrm{b}}$ with the density of the diesel fuel $\rho_{\mathrm{b}}$ gives the volume flow of diesel fuel burned $\dot{V}_{\mathrm{b}}$. The density is assumed to be constant with a value of $836.8 \mathrm{~kg}$ per $\mathrm{m}^{3}$ diesel:

$\dot{V}_{\mathrm{b}}=\frac{\dot{m}_{\mathrm{b}}}{\rho_{\mathrm{b}}}$.

Integrating $\dot{V}_{\mathrm{b}}$ gives the total fuel consumed in the simulated cycle:

$V_{\mathrm{b}}=\int \dot{V}_{\mathrm{b}} \mathrm{d} t$

\subsubsection{Charge-depleting}

At the end of the simulation, two values are obtained which express the energy consumption of the hybrid machines. It is the amount of diesel fuel burned $V_{\mathrm{b}}$ in liter and the battery energy $E_{\mathrm{Batt}-\mathrm{pH}}$ in $\mathrm{kWh}$. These two values represent the charge-depleting-mode (CD-mode) where the battery is not recharged actively in the machine.

\subsubsection{Charge-sustaining}

To be able to compare the hybrid system with the current machine in terms of fuel consumption, it is necessary to transfer the battery energy used into an equivalent amount of fuel. It gives an idea of how much fuel is needed if the battery is never recharged from an external source but in the machine itself. The recalculation is based on the mean 


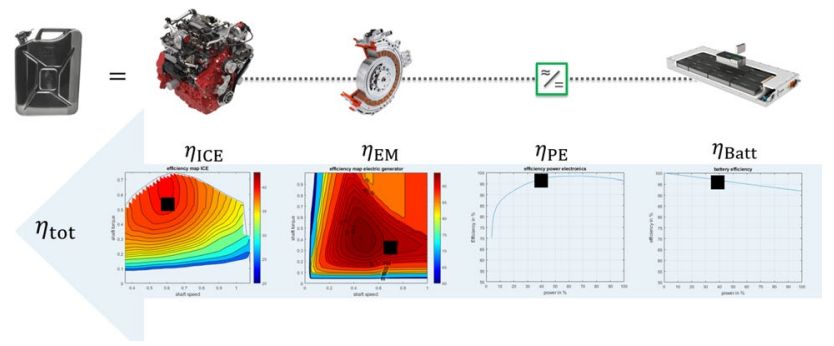

Fig. 7 Calculation of the fuel equivalence factor

efficiencies of all related power converters in the previous simulated cycle (Fig. 7):

$\bar{\eta}_{\mathrm{tot}}=\bar{\eta}_{\mathrm{Batt}} \cdot \bar{\eta}_{\mathrm{PE}} \cdot \bar{\eta}_{\mathrm{EM}-\mathrm{pH}} \cdot \bar{\eta}_{\mathrm{ICE}} \cdot$

Dividing the total amount of battery energy consumed in the cycle $E_{\text {Batt }}$ by the mean efficiency $\bar{\eta}_{\text {tot }}$, the lower heating value of diesel $H_{\mathrm{u}}=42.55 \mathrm{MJ} / \mathrm{kg}$ and the fuels density $\rho_{\mathrm{b}}$ gives the equivalent fuel volume $V_{\mathrm{b}, \mathrm{Batt}}$ in liter diesel:

$V_{\mathrm{b}, \text { Batt }}=\frac{E_{\text {Batt-pH }}}{\bar{\eta}_{\text {tot }} \cdot H_{\mathrm{u}} \cdot \rho_{\mathrm{b}} \cdot 3600}$.

The total amount of fuel consumed by the downsized hybridICE $V_{\mathrm{b}}$ and the equivalent amount of fuel $V_{\mathrm{b}, \text { Batt }}$ gives the total fuel consumed in charge-sustaining-(CS)-mode $V_{\mathrm{b}, \mathrm{CS}}$ in liter diesel:

$V_{\mathrm{b}, \mathrm{CS}}=V_{\mathrm{b}}+V_{\mathrm{b}, \mathrm{Batt}}$.

This assumption is reasonable if the required mean effective power is below the full-load capability of the ICE. Otherwise, fully recharging the battery would not be possible thus limiting the operating time.

\subsection{Series hybrid}

The series hybrid powertrain is evaluated in almost the same way as the parallel hybrid is. The results of the simulation are as well two values: the CD-value (see Sect. 2.3.1) and CS-value (see Sect. 2.3.2). However, the powertrain structure differs in the arrangement of the drive train components (Fig. 8). Instead of keeping the series arrangement of a hydraulic pump and motor, two electric motors are used: one working in most of the use cases as generator and the other as propulsion motor at the cardan shaft. The ICE size remains the same as for the parallel hybrid and is reduced by $25 \%$ in power $(75 \mathrm{~kW})$. The power required above the full-load curve of the engine is supplied by the battery and recalculated with the equivalence factor at the end of the simulation.

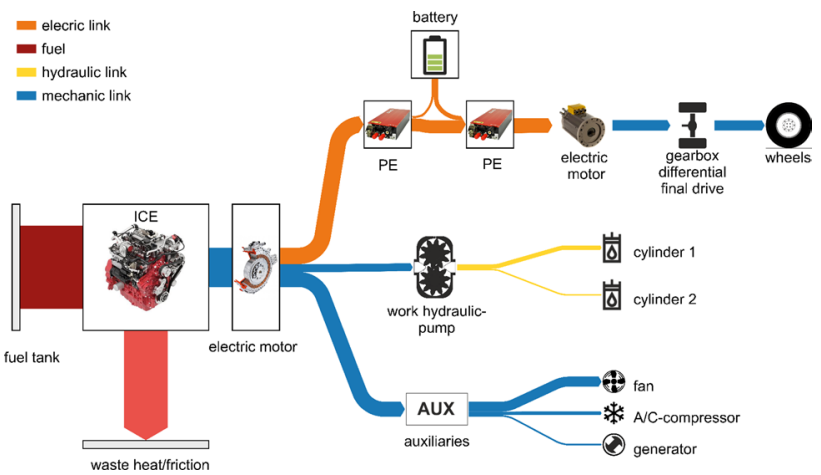

Fig. 8 Powertrain structure of the series hybrid

For the parallel hybrid, the point of equivalent power was at the common shaft of electric motor and ICE; it is the crankshaft. For the series hybrid, it is as well except that the effective series-ICE power $P_{\text {ICE-sH }}$ is lower due to efficiency improve in the drive train. The maximum recuperation power $P_{\text {Recup }}$ is changing as well due to the shortened efficiency chain:

$P_{\text {Hyb,eff }}=P_{\text {ICE-sH }}-\left|P_{\text {Recup }}\right|$.

To calculate the lower power demand of the ICE $P_{\text {ICE-sH }}$, the sum of power consumed by the work hydraulic system and auxiliaries $P_{\mathrm{WH}, \mathrm{AUX}}$ (see Eq. 4 ) and the effective power to propel the series electric drive train $P_{\mathrm{DT}-\mathrm{sH}}$ is formed. The work hydraulic system and the auxiliary arrangement is assumed to stay the same:

$P_{\mathrm{ICE}-\mathrm{sH}}=P_{\mathrm{WH}, \mathrm{AUX}}+P_{\mathrm{DT}-\mathrm{sH}} \cdot$

$P_{\text {DT-sH }}$ is obtained by dividing the effective power at the output shaft of the hydraulic motor $P_{\mathrm{HM} \text {,eff }}$ (see Eq. 2) with the total efficiency of the electric drive train $\eta_{\text {el,tot }}$. Using the power $P_{\mathrm{HM} \text {,eff }}$ secures that the same effective power is used to propel the cardan shaft and thus the wheels:

$P_{\mathrm{DT}-\mathrm{sH}}=\frac{P_{\mathrm{HM}, \mathrm{eff}}}{\eta_{\mathrm{el}, \mathrm{tot}}}$.

$\eta_{\mathrm{el}, \text { tot }}$ is the calculated efficiency of the two electric motors arranged in series: one working in most of the time as generator, called working motor (WM), and the second as propulsion motor for the wheels, called traction motor (TM). In the calculations, the power electronics is taken into account, as well:

$\eta_{\mathrm{el}, \mathrm{tot}}=\eta_{\mathrm{WM}} \cdot \eta_{\mathrm{PE}} \cdot \eta_{\mathrm{TM}} \cdot$

The recuperation power $P_{\text {Recup }}$ in Eq. (25) is obtained in a similar way as for the parallel hybrid (see Eq. 14). However, two important values are changing, the maximum 
recuperation power $P_{\mathrm{EM} \text {,max }}$ and the mean efficiency of the hydraulic motor $\bar{\eta}_{\mathrm{HM} \text {, mean }}$ which is assumed to be $74 \%$. Additionally, instead of multiplying with the efficiency $\bar{\eta}_{\mathrm{HP}, \text { mean }}$, as in case of the parallel hybrid, the measured hydraulic power is divided by the mean efficiency of the hydraulic motor $\bar{\eta}_{\mathrm{HM} \text {,mean }} . \bar{\eta}_{\mathrm{HM} \text {,mean }}$ is used, because the point of recuperation moves closer to the wheels and with that the efficiency chain shortens. More recuperable power than with a parallel hybrid is possible, because the traction motor is sized for its maximum propulsion power (here $70 \mathrm{~kW}$ ). For short periods, an overload factor of 2 is assumed to be possible, resulting in the value of $P_{\mathrm{EM} \text {, } m a x}=140 \mathrm{~kW}$ :

$P_{\text {Recup }}=\max \left(\frac{P_{\mathrm{Hyd}}<0}{\bar{\eta}_{\mathrm{HP}, \text { mean }}}, P_{\mathrm{EM}, \text { max }}\right)$.

The effective power to be generated by the hybrid system at the common shaft $P_{\mathrm{Hyb}, \mathrm{eff}}$ is determined by Eq. (25). Based on the same calculation procedure as described in Sect. 2.3, parallel hybrid starting at Eq. (15) is calculated. All demanded power above the full-load curve of the ICE is supplied by the battery.

The results of the calculation are the total energy consumed by the ICE and the battery in CD-mode. The recalculated fuel equivalent of the battery energy plus the consumption of the hybrid-ICE gives the total fuel consumed in CS-mode.

To compare the energy consumption of the battery electric machine with the ICE-based machines, it is useful to recalculate the liter diesel fuel consumed on the basis of the lower heating value $H_{\mathrm{u}}$ and density $\rho_{\mathrm{b}}$ into $\mathrm{kWh}$ :

$E=V_{\mathrm{b}} \cdot \frac{H_{\mathrm{u}} \cdot \rho_{\mathrm{b}}}{3600}$.

\subsection{Tank-to-wheel}

Additionally, in this study, a $\mathrm{CO}_{2}$-based comparison is carried out. The energy consumed in form of diesel fuel and electricity is transferred into an equivalent amount of $\mathrm{CO}_{2}$. Tank-to-wheel ( $\mathrm{TtW}$ ) emissions only take the part of the emissions into account that the machine emits during its operation, but are the basis for the following extended well-to-wheel analysis. $\mathrm{CO}_{2}$ emissions are taken into account, and restricted emissions like hydrocarbons and nitrogen oxide are not considered. The amount of diesel combusted correlates linearly with $\mathrm{CO}_{2}$. It is assumed that $86 \%$ mass fraction of diesel fuel $\left(\mu_{\mathrm{C}}\right)$ is carbon. This leads in combination with the molar mass of $\mathrm{CO}_{2} M_{\mathrm{CO}_{2}}=$ $44 \mathrm{~kg} / \mathrm{kmol}$ and carbon $M_{\mathrm{C}}=12 \mathrm{~kg} / \mathrm{kmol}$ to $2.64 \mathrm{~kg} \mathrm{CO}_{2}$ emissions per liter diesel fuel:
$m_{\mathrm{CO}_{2}, \text { diesel }}=\mu_{\mathrm{C}} \cdot \frac{M_{\mathrm{CO}_{2}}}{M_{\mathrm{C}}} \cdot \rho_{\mathrm{b}}=2.64$

Current legislation for passenger cars and heavy duty vehicles considers $\mathrm{CO}_{2}$ emissions in a TtW point of view. Limits are set for the average values of the whole sold vehicle fleet. For TtW emissions, it is neglected how the fuel or electricity is produced, which means that the electric drive train emits zero emissions. It is therefore necessary to differentiate between restricted emissions by legislation and the real emissions obtained by taking an overall point of view.

\subsection{Well-to-wheel}

Well-to-wheel (WtW) emissions are showing a more global perspective. The established term WtW contains the emissions starting from the fuel/energy production to combustion/ transformation in the vehicle. In the course of the study, the term $\mathrm{WtW}$ includes the emissions related to the battery production, as well. The reason to include only the battery production is that investigations in the passenger car sector show that the main difference comparing total $\mathrm{CO}_{2}$ emissions of conventional and battery electric vehicle is the battery [16]. The production of the vehicle body, the drive train, as well as the disposal are approximately the same.

The production of the electricity used for recharging the battery of the electric drive as well as the hybrid machine in $\mathrm{CD}$-mode is based on $\mathrm{CO}_{2}$-emission factors. For Austria (AT), $258 \mathrm{~g} \mathrm{CO}_{2}$ per $\mathrm{kWh}$ electrical energy is assumed [14]. The average value for European Union (EU) electricity production, as well as the value for Poland (PL), are based on a study of the Joint Research Center (JRC) providing numbers of emissions of the member states after trading in the year 2013 [15]. The average value for the $\mathrm{EU}$ is $447 \mathrm{~g} \mathrm{CO}_{2}$ per $\mathrm{kWh}$, and for Poland, it is $980 \mathrm{~g} \mathrm{CO}_{2}$ per $\mathrm{kWh}$, since they have a high share of coal power plants.

For the battery production, $150 \mathrm{~kg} \mathrm{CO}_{2}$ per $\mathrm{kWh}$ is used and is the mean value of a number of studies ranging from 100 to $200 \mathrm{~kg} \mathrm{CO}_{2}$ per $\mathrm{kWh}$ [16]. The battery size for a battery electric drive is scaled to fulfil an 8-h work day and is $320 \mathrm{kWh}$. An assumed lifetime of 10,000 working hours thus leads to 4.8 $\mathrm{kg} \mathrm{CO}_{2}$ emissions per operating hour for the battery electric drive. The assumed battery size for the hybrid powertrains is $40 \mathrm{kWh}$ and leads to $0.6 \mathrm{~kg} \mathrm{CO}_{2}$ emissions per operating hour. Twelve percent charging losses are taken into account as well [17]. The production of diesel fuel leads to $10 \%$ losses in primary energy during production, transport, and dispensing [18]. 


\section{Results}

\subsection{Energy-based comparison}

The energy amount consumed by the different propulsion systems is listed in Table 1. The current ICE-driven machine consumes $98.8 \mathrm{kWh}$ of diesel fuel per hour in a Y-cycle. An electric machine consumes $69 \%$ less energy supplied from an external source. Looking isolated at the efficiency of the machine itself, an electric drive is the most efficient one.

A parallel hybrid is able to save $12 \%$ of supplied fuel energy compared to the current machine when running in CD-mode (see Sect. 2.3.1). However, this is only possible if the battery energy used is supplied by an external power source (e.g., power grid or photovoltaic system). If the amount of $3.2 \mathrm{kWh}$ used battery energy is regenerated in the machine itself, only a slight improvement of $0.8 \%$ remains compared to the current machine.

Series hybrid machines lead to fuel savings of $20 \%$ compared to the current machine in CD-mode. Even recharging the $1.2 \mathrm{kWh}$ of used battery energy in the machine leads to $16 \%$ improvement in fuel consumption in CS-mode.

There are three main reasons why the series hybrid system is outperforming the parallel hybrid one. Two important reasons can be found already by comparing the cumulated battery power of the parallel and series hybrid. One reason is that the series hybrid system is able to recuperate more energy in the drive train and thus consumes less battery energy. That is because the point of recuperation is closer at the wheels, therefore having the advantage of a shorter recuperation efficiency chain. Figure 9 illustrates in a simplified way by just using the maximum possible efficiency of each energy converter. This leads to the maximum efficiency for recuperation $\eta_{\text {tot }}$ from the wheels to the battery (black line in Fig. 9). To reuse the recuperated energy, the path battery to the wheels is passed through again and leads to maximum reuse efficiency of the studied

Table 1 Supplied energy in $\mathrm{kWh}$ per hour for different propulsion systems in a Y-cycle

\begin{tabular}{|c|c|}
\hline & Diesel fuel Electric energy \\
\hline ICE & 98.8 \\
\hline Battery electric drive & 31.0 \\
\hline Parallel hybrid & $\begin{array}{r}86.7 \mid 3.2^{\mathrm{a}} \\
98.0^{\mathrm{b}}\end{array}$ \\
\hline Series hybrid & $\begin{array}{l}79.0 \mid 1.2^{\mathrm{a}} \\
83.4^{\mathrm{b}}\end{array}$ \\
\hline
\end{tabular}

${ }^{\text {a } C h a r g e-d e p l e t i n g ~(s e e ~ S e c t . ~ 2.3 .1) ~}$

${ }^{\mathrm{b}}$ Charge-sustaining (see Sect. 2.3.2)

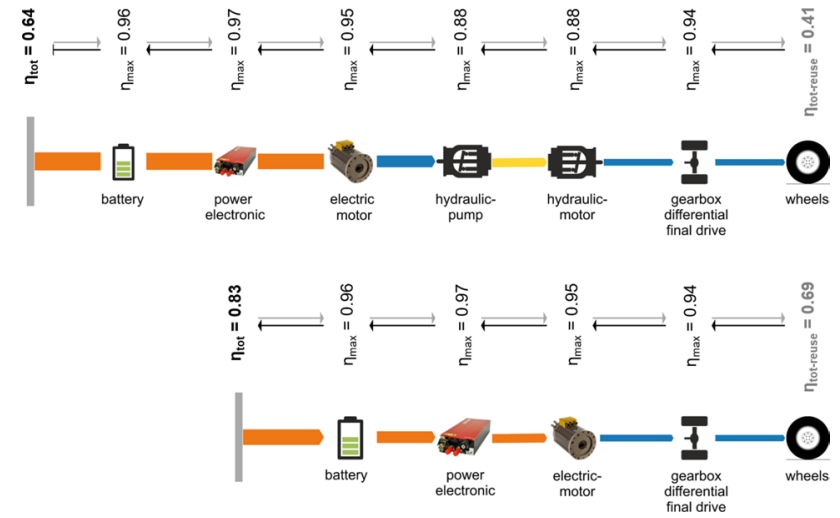

Fig. 9 Maximum efficiency chain of recuperation in the drive train of a parallel hybrid (top) and series hybrid (bottom) [8, 19]

powertrain $\eta_{\text {tot-reuse }}$ (gray line in Fig. 9). In the very best case, only $41 \%$ of the originally available recuperation energy can be reused at the wheel in a parallel, and $69 \%$ in a series hybrid.

As a second reason, the maximum recuperation power of the electric machine $P_{\mathrm{EM}, \max }$ in the series hybrid is higher. It is scaled to fulfill all required driving tasks. For the third and main reason, the series arrangement of two electric motors instead of the conventional hydrostatic drive is more efficient in propulsion mode.

\section{2 $\mathrm{CO}_{2}$-based comparison}

The TtW emissions in terms of $\mathrm{CO}_{2}$ are mirroring the results of the energetic comparison (Table 2). A battery electric machine is the best, because it locally runs emission-free. This is because $\mathrm{TtW}$ considerations as mentioned before

Table $2 \mathrm{CO}_{2}$ emissions in $\mathrm{kg} \mathrm{CO} 2$ per hour for different propulsion systems in a Y-cycle

\begin{tabular}{rcc} 
& Tank-to-wheel & Well-to-wheel \\
\hline \multirow{2}{*}{ ICE } & 26.4 \\
& & $29.3^{\mathrm{a}}$ \\
\hline \multirow{2}{*}{ Battery electric drive } & 0 & $20.6^{\mathrm{b}}$ \\
\hline \multirow{2}{*}{ Parallel hybrid } & $23.1(\mathrm{CD})$ \\
& $26.1(\mathrm{CS})$ \\
& $27.9(\mathrm{CD})^{\mathrm{a}, \mathrm{b}}$ \\
& $29.6(\mathrm{CS})^{\mathrm{a}}$ \\
\hline \multirow{2}{*}{ Series hybrid } & $21.1(\mathrm{CD})$ \\
& $22.3(\mathrm{CS})$ \\
& $24.6(\mathrm{CD})^{\mathrm{a}, \mathrm{b}}$ \\
& $25.3(\mathrm{CS})^{\mathrm{a}}$ \\
\hline
\end{tabular}

$C D$ Charge-depleting (see Sect. 2.3.1), CS Charge-sustaining (see Sect. 2.3.2)

${ }^{\mathrm{a}}$ Well-to-tank efficiency $=90 \%, 2019$ [18]

${ }^{\mathrm{b}} \mathrm{EU} 28$ average, 2013 (447 $\left.\mathrm{g} \mathrm{CO}_{2} / \mathrm{kWh}\right)$ [15] 
only represent emissions a machine emits when operating thus neglecting how the energy carrier is produced. For diesel-driven machines, the amount of fuel energy consumed correlates linearly with the $\mathrm{CO}_{2}$ emissions. That means the current machine propelled by a diesel engine with $100 \mathrm{~kW}$ power emits $26.4 \mathrm{~kg} \mathrm{CO}_{2}$ per operating hour in a Y-cycle.

A parallel hybrid system by contrast is able to save $12 \%$ $\mathrm{CO}_{2}$ in $\mathrm{CD}$-mode when being recharged from an external source. This is mainly because of the reduced engine size $(75 \mathrm{~kW})$. The advantage shrinks down to $0.8 \%$ when looking at the CS-mode, where the used battery energy is regenerated onboard. In comparison to that, a series hybrid saves $20 \% \mathrm{CO}_{2}$ in $\mathrm{CD}$-mode. If there is no possibility to recharge the battery from an external source and instead is reloaded from the generator driven by the ICE (CS-mode), $16 \%$ can be saved compared to the current machine.

Assessed in terms of $\mathrm{WtW}$, the current machine emits $29.3 \mathrm{~kg} \mathrm{CO}_{2}$ per operating hour in a Y-cycle (Table 2). This is $10 \%$ above the $\mathrm{TtW}$-emission value and represents the additional emissions related to the fuel production, fuel transport, and fuel dispensing.

Battery electric-driven machines are surprising in terms of $\mathrm{WtW} \mathrm{CO}_{2}$ emissions. They set the lowest ( $-53 \%$ compared to the current machine) as well as the highest possible (+34\%) $\mathrm{CO}_{2}$ emissions of all considered powertrains (Table 3). That means it is better to operate a current ICE-based machine instead of a battery electric machine recharged with electricity produced by coal power plants. The most representative result is the value calculated on the basis of the European average electricity production which gives a minus of $30 \%$ compared to the current machine (Table 2).

In terms of $\mathrm{WtW}-\mathrm{CO}_{2}$ emissions, parallel hybrid-drive trains are able to save $7 \%$ in comparison to the current

Table 3 Well-to-wheel $\mathrm{CO}_{2}$ emissions in $\mathrm{kg} \mathrm{CO}_{2}$ per hour for different propulsion systems in a Y-cycle with varying electricity production

\begin{tabular}{|c|c|}
\hline & Well-to-wheel \\
\hline \multirow{3}{*}{ Battery electric drive } & $13.9^{c}$ \\
\hline & $20.6^{\mathrm{b}}$ \\
\hline & $39.4^{\mathrm{d}}$ \\
\hline \multirow{3}{*}{ Parallel hybrid } & $27.2(\mathrm{CD})^{\mathrm{a}, \mathrm{c}}$ \\
\hline & $27.9(\mathrm{CD})^{\mathrm{a}, \mathrm{b}}$ \\
\hline & $29.9(\mathrm{CD})^{\mathrm{a}, \mathrm{d}}$ \\
\hline \multirow{3}{*}{ Series hybrid } & $24.4(\mathrm{CD})^{\mathrm{a}, \mathrm{c}}$ \\
\hline & $24.6(\mathrm{CD})^{\mathrm{a}, \mathrm{b}}$ \\
\hline & $25.4(\mathrm{CD})^{\mathrm{a}, \mathrm{d}}$ \\
\hline
\end{tabular}

CD Charge-depleting (see Sect. 2.3.1)

${ }^{\mathrm{a}}$ Well-to-tank efficiency $=90 \%, 2019$ [18]

${ }^{\mathrm{b}} \mathrm{EU} 28$ average, 2013 (447 $\left.\mathrm{g} \mathrm{CO}_{2} / \mathrm{kWh}\right)$ [15]

${ }^{\mathrm{c}} \mathrm{AT}, 2020\left(258 \mathrm{~g} \mathrm{CO}_{2} / \mathrm{kWh}\right)$ [14]

${ }^{\mathrm{d}} \mathrm{PL}, 2013$ (980 $\left.\mathrm{g} \mathrm{CO}_{2} / \mathrm{kWh}\right)$ [15] machine if the amount of $3.2 \mathrm{kWh}$ of battery energy are recharged with electricity produced in Austria (Table 3). However, recharging with an electricity production mainly based on coal power (represented by Poland) leads to a surplus of $2 \%$. Recharging with the European average value shows a 5\% improvement. The CS-value, representing a recharging in the machine with the mean efficiencies of the last cycle, gives a surplus of $1 \%$ (Table 2). The reason for this is the consideration of the fuel production and the amount of $\mathrm{CO}_{2}$ representing the production of the $40 \mathrm{kWh}$ battery.

In comparison to that, in the best case, a series hybrid being recharged from an external source emits $17 \%$ less $\mathrm{CO}_{2}$ compared to the current machine; in the worst case, it is still $13 \%$ less (Table 3 ). Recharging with a European average value leads to a minus of $16 \%$. In CS-mode, the $\mathrm{WtW}$ emissions are still $14 \%$ less than the current machine (Table 2).

\section{Discussion}

Although the battery electric machine is able to save $30 \%$ of $\mathrm{CO}_{2}$ emissions (EU), difficulties are arising with regard to other aspects. First, the economic viability is not given so far. The battery costs are too high to provide a vehicle for an 8-h work day, regardless of the size of the vehicle. Figure 10 shows a simplified calculation of the battery costs.

It is assumed that the main power source, an ICE, is replaced by an electric motor and a battery. Based on the mean fuel consumption of the current machine, the battery price can be obtained on the $y$-axis by choosing the operating time necessary. For example, assuming a machine with an average consumption of 101 diesel fuel running for $8 \mathrm{~h}$, the battery would cost around 50,000 $€$. This is more than half of the purchase price for a machine of that size. The assumptions made for this calculation are stated on top of Fig. 10. The most important factor for economic viability

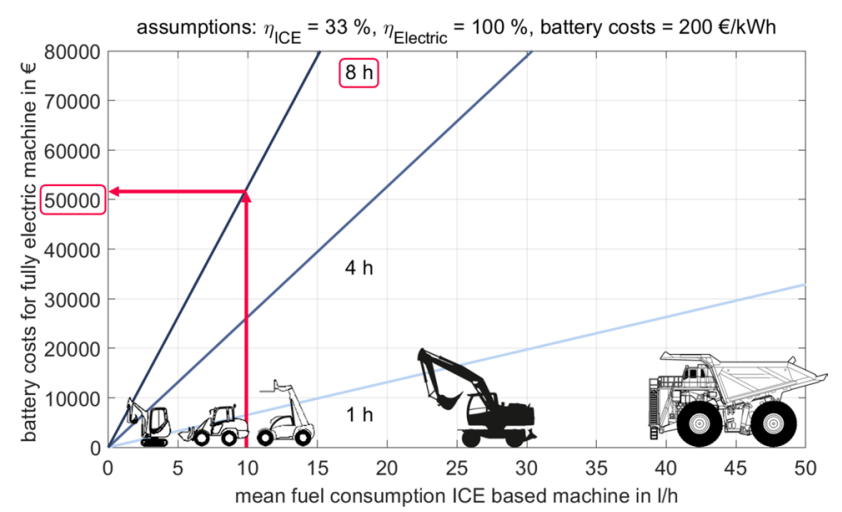

Fig. 10 Battery price for replacing the ICE with an electric machine and a battery depending on the operating time 
is the battery system costs which are assumed to be $200 € /$ $\mathrm{kWh}$. This is a value set low already, bearing in mind that a battery system for a construction machine needs to be more robust and needs to have a longer lifetime than in a battery electric passenger car. Additionally, the battery system needs to be developed for each machine category and has a low number of production units.

Second recharging at the construction site is an issue, as well. In Fig. 11, refuelling a diesel drive train and a battery electric drive train is shown to compare the operating time after 1 min of refuelling for a machine with a mean effective power of $42 \mathrm{~kW}$. In the best case using a fast charging system with $300 \mathrm{~kW}$ charging power, the electric machine is able to operate $6 \mathrm{~min}$ after refuelling for $1 \mathrm{~min}$. Recharging with a widely available power of $22 \mathrm{~kW}$ gives $27 \mathrm{~s}$ of operating time. The high-energy density of diesel leads to a refuelling power of $30,000 \mathrm{~kW}$ and thus to an operating time of more than $3 \mathrm{~h}$ after $1 \mathrm{~min}$ of refuelling.

A parallel hybrid as studied here with a $25 \%$ reduced diesel engine size and an electric motor does not achieve that much of an advantage in terms of $\mathrm{CO}_{2}$. One of the reasons why a parallel hybrid system achieves advantages in the passenger car sector is because they are often built in combination with a gasoline engine. Advantages can be generated when low-load operating points with poor efficiency are electrically driven and the electric energy used is regenerated at high-load operating points with high efficiency. A large difference in efficiency between low and high load is therefore the prerequisite. Diesel engines have a very flat efficiency map, because throttling is not necessary. Nevertheless, the evaluation methodology used here is not suitable for assessing load point shifting, since the recalculation of the used battery energy is based on mean values. However, the potential for load point shifting in this particular operational cycle is rather low, since the average efficiency of the hybrid-ICE in the propulsion sections is due to downsizing already $38 \%$. The difference to the best efficiency of the hybrid-ICE is therefore only about $3 \%$ points.
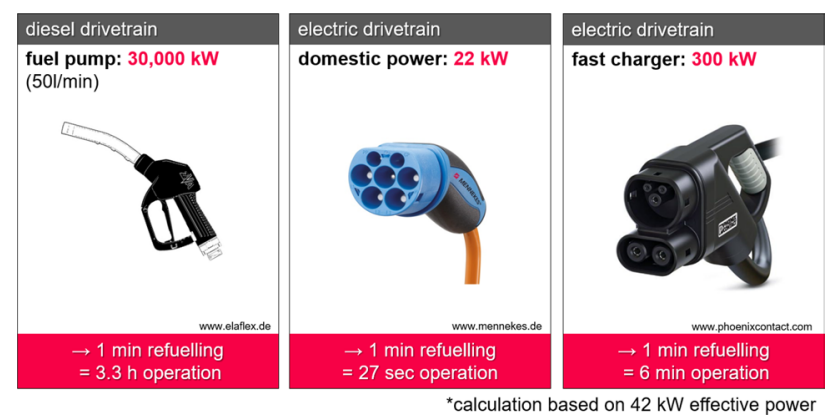

Fig. 11 Comparison of operating time after $1 \mathrm{~min}$ of refuelling for different technologies
The best choice between $\mathrm{CO}_{2}$ saving potential and feasibility is the series hybrid machine. $17 \%$ of $\mathrm{CO}_{2}(\mathrm{WtW})$ can be saved compared to a current machine if the amount of 1.2 $\mathrm{kWh}$ of battery energy used is recharged with electricity produced in Austria. Recharging with the average value of the European Union leads to an improvement of $16 \%$. It is better to recharge the amount of electric energy in the machine itself than recharging with electricity produced mainly based on coal power. That means it is better to recharge the battery with the diesel engine than recharging with coal power electricity.

Basically, a single-point operation mode (e.g., best efficiency point of the ICE) would be possible in case of a series hybrid. However, this is only possible in driving situations where the working hydraulic system is not addressed; otherwise, it determines the rotational speed of the engine to achieve the necessary volume flow. The difference between the average operating point and the best efficiency point of the hybrid-ICE in the Y-cycle is $3.5 \%$ points. It also has to be noted that it is better (in terms of overall efficiency) to use generated electrical energy directly in the drive train, because every energy conversion means additional losses. Therefore, a single-point operation mode is not considered to be favourable.

The additional costs due to the small battery pack size $(40 \mathrm{kWh})$ and the $\mathrm{CO}_{2}$ burden are rather low compared to a battery electric machine. The refuelling time is low and the operating time is not limited, because the battery can also be recharged in the hybrid itself. Even short time emissionfree propulsion is possible (depending on the battery size). To recharge the battery from an external power source, the vehicle must be stationary and cannot be operated, which means that CS-mode is probably used most of the time. To conclude, a series hybrid-drive train with a plug-in capability is the most advantageous powertrain for non-road mobile machinery with a high share of driving tasks.

Further research should be undertaken to investigate the additional advantage possible through the usage of alternative fuels. Their potential for the future of drive trains with high-power demand can be expected to be considerable, since these fuels are produced based on renewable energy. Hydrogen produced with renewable energy as well as tailor-made liquid fuels in combination with $\mathrm{a} \mathrm{CO}_{2}$ capturing technology are promising to save a high amount of $\mathrm{CO}_{2}$-emissions. In addition, especially liquid fuels could rely on an already existing infrastructure.

\section{Conclusion}

NRMM consume $11 \%$ of diesel fuel consumed in passenger and goods transport and therefore emit $2 \%$ of overall European $\mathrm{CO}_{2}$ emissions [1]. As there are already $\mathrm{CO}_{2}$-limiting 
legislations introduced for passenger cars and heavy duty vehicles, similar laws are expected to be implemented for mobile machinery, as well.

There are two different approaches used to evaluate the $\mathrm{CO}_{2}$ emissions of the machine, tank-to-wheel, and an extended well-to-wheel assessment. The difference is that a TtW approach is not considering the production of the energy carrier and therefore overestimates the $\mathrm{CO}_{2}$-saving potential of all electrified powertrains but especially the battery electric drive. $\mathrm{TtW}$ is also the approach that is used to assess the $\mathrm{CO}_{2}$ emissions in the current $\mathrm{CO}_{2}$-limiting legislations for passenger cars and heavy duty vehicles. Battery electric drives thus have the advantage of being considered as zero emission powertrains. Assessing the emissions with the extended $\mathrm{WtW}$ approach proposed in this study, a different picture is shown. Including the production of the energy carrier (electricity or diesel fuel), the battery production, and recharging losses, electric drives set the values for the lowest as well as the highest possible $\mathrm{CO}_{2}$ emissions. The large spread is mainly caused by the electricity generation. However, recharged with European averaged electricity, a reduction of $30 \%$ is possible compared to the current diesel-based machine. However, electric drive trains face other challenges in relation to their main component, the battery. Due to the high battery costs, an economically viable implementation of the electric drive is a major difficulty. The question of recharging at a construction site in terms of available grid power and charging time is an open issue, as well.

By contrast in a TtW point of view, a parallel hybrid saves $12 \%$ in CD-mode, but only $1 \%$ in CS-mode. The reason is the inefficient use of recuperable energy due to long-efficiency chains and the limited maximum power of the electric motor. Assessing the $\mathrm{CO}_{2}$ emissions in terms of $\mathrm{WtW}$ leads to minus $5 \% \mathrm{CO}_{2}$ emissions in $\mathrm{CD}$-mode (EU) but even a surplus of $1 \%$ in CS-mode. Parallel hybrid systems for wheel-driven construction machinery are therefore not an optimal solution. However, it has to be noted that the evaluation method used in this study is not suitable to discuss load point shifting. The method shown recalculates the used battery energy on the basis of mean values of the simulated Y-cycle.

Moving on to a series hybrid propulsion system, in a $\mathrm{TtW}$ point of view, it is able to save $20 \%$ fuel compared to a current machine in CD-mode. Running in CS-mode, where electric energy used is regenerated in the vehicle, $16 \%$ of fuel can be saved. Also the WtW emissions show a high possible improvement of $14 \%$ in CS-mode and $16 \%$ in CD-mode (EU). This is mainly because of the improved efficiency in the drive train and the capability of recuperating energy. With a small battery ( $40 \mathrm{kWh}$ assumed), it is even possible to run the machine for a limited period purely by electric drive. In conclusion, the study shows that series hybrid powertrains unite the advantages of an ICE-based drive drain (unlimited working time and quick refuelling) with those of a battery electric drive (high efficiency and energy recuperation) and, thus, constitute a promising solution for the future of wheel-driven mobile machinery.

Acknowledgements This project was supported by the Austrian Society of Automotive Engineers (ÖVK) and Liebherr Werk Telfs GmbH. The authors express their thanks to them.

Funding Open access funding provided by Graz University of Technology.

Open Access This article is licensed under a Creative Commons Attribution 4.0 International License, which permits use, sharing, adaptation, distribution and reproduction in any medium or format, as long as you give appropriate credit to the original author(s) and the source, provide a link to the Creative Commons licence, and indicate if changes were made. The images or other third party material in this article are included in the article's Creative Commons licence, unless indicated otherwise in a credit line to the material. If material is not included in the article's Creative Commons licence and your intended use is not permitted by statutory regulation or exceeds the permitted use, you will need to obtain permission directly from the copyright holder. To view a copy of this licence, visit http://creativecommons.org/licenses/by/4.0/.

\section{References}

1. Vandenbroucke, D., Van Hyfte, A., Francx, L.: Study in View of the Revision of Directive 97/68/EC on Non-Road Mobile Machinery-Final Report Module 1-An Emissions Inventory. Arcadis, Belgien (2010)

2. European Commission: Vehicle Energy Consumption Calculation Tool-VECTO. https://ec.europa.eu/clima/policies/transport/ vehicles/vecto_en. Accessed 11 May 2020

3. Schneider, M.: Erstellung und Optimierung einer Hybrid-Betriebsstrategie von Non-Road-Arbeitsmaschinen mittels Simulation und Prüfstandsmessung, Graz University of Technology, Institute of Internal Combustion Engines and Thermodynamics, Master thesis, Graz (2014)

4. Nagel, P.: Entwicklung einer Betriebsstrategie zur Energierückgewinnung in hybriden Mehrverbrauchersystemen, Karlsruher Institut für Technologie, Dissertation, Karlsruhe (2015)

5. Linder, M., Wöbcke, S., Striller, B., Herlitzius, T.: Dieselelektrischer Fahrantrieb für Rübenvollernter. Springer, Wiesbaden (2012)

6. Kagoshima, M.: The development of an 8 tonne class hybrid hydraulic excavator SK80H, Kobelco Technology Review (2013)

7. Guzzella, L., Sciaretta, A.: Vehicle Propulsion Systems, 3rd edn. Springer, Heidelberg (2013). (ISBN 978-3-642-35912-5)

8. Bagusch, J., Rahmfeld, R., Göllner, W.: Neue Antriebsstrategien für Radlader mit hydrostatischem Getriebe. Fachtagung Hybride und energieeffiziente Antriebe für Mobile Arbeitsmaschinen. Danfoss Power Solutions GmbH, Karlsruhe (2019)

9. Parker Manufacturer Homepage: Technical manual. http://www. parker.com/literature/Electromechanical\%20Europe/User\%20Gui des/PVD3668_GB\%20GVM.pdf. Accessed 06 Apr 2020

10. Fuchs, J.: Optimal energy management for hybrid electric vehicles. Graz University of Technology, Institute of Electrical Measurement and Sensor Systems, Dissertation, Graz (2016)

11. Schweighofer, B., Wegleiter, H., Recheis, M., Fulmek, P.: Fast and accurate battery model applicable for EV and HEV simulation. In: 
Instrumentation and Measurement Technology Conference, Graz (2012)

12. Panasonic Manufacturer Homepage: Product sheet. https://indus trial.panasonic.com/www/products/ batteries/secondary-batteries/ lithium-ion/cylindrical-type/UR18650ZTA. Accessed 29 Mar 2019

13. Fischer, R.: Elektrische Maschinen, Carl Hanser Verlag München, S.235, 2017, e-ISBN: 978-3-446-45295-4

14. Environment Agency Austria Homepage: $\mathrm{CO}_{2}$-Calculator. https:// secure.umweltbundesamt.at/co2mon/co2mon.html. Accessed 08 June 2020

15. Moro, A., Lonza, L.: Electricity Carbon Intensity in European Member States: Impacts on GHG Emissions of Electric Vehicles. European Commission, Joint Research Centre (JRC), Ispra (2017)

16. Helms, H., Kämper, K., Biemann, K., Lambrecht, U., Jöhrens, J.: Klimabilanz von Elektroautos - Einflussfaktoren und Verbesserungspotenzial, Institut für Energie- und Umweltforschung Heidelberg GmbH under the authority of Agora Verkehrswende, 2019
17. Apostolaki-Iosifidou, E., Codani, P., Kempton, W.: Measurement of Power Loss During Electric Vehicle Charging and Discharging. Elsevier Scientific Publication Company, Amsterdam (2017)

18. Warnecke, W., Adolf, J., Balzer, C.H., Xiao, F., Hagenow, G., Hemberger, Y., Janssen, A., Klokkenburg, M., Van der Made, A., McKnight, T.: The road to sustainable fuels for zero emissions mobility, shell global solutions, published by Austrian Society of Automotive Engineers (ÖVK) (2019)

19. Kasper, R., Schünemann, M.: 5. Elektrische Fahrantriebe Topologien und Wirkungsgrad, Springer Vieweg, MTZ-Motorentechnische Zeitschrift 73, Issue 10: S.802-807, Wiesbaden, 2012

Publisher's Note Springer Nature remains neutral with regard to jurisdictional claims in published maps and institutional affiliations. 